\title{
A systematic review on the implication of Candida in peri-implantitis
}

\author{
Irene Lafuente-Ibáñez de Mendoza', Amaia Cayero-Garay' ${ }^{1}$, Guillermo Quindós-Andrés ${ }^{2}$ and \\ José Manuel Aguirre-Urizar ${ }^{1 *}$
}

\begin{abstract}
Background: Candida is a heterogeneous fungal genus. Subgingival sulcus is a refuge for Candida, which has already been related to the pathogenic inflammation of periodontitis. This work aims to review the presence of Candida in the sulcular fluid surrounding dental implants and discuss its potential role in peri-implantitis.

Results: A bibliographical research was performed in PubMed, Scopus and Web of Science databases, with the keywords candida, peri-implantitis, periimplantitis, "dental implant" and implant. Newcastle-Ottawa Scale was used to assess the methodological quality of the included studies. At the end, nine observational studies were included, which analysed 400 dental implants with PI and 337 without peri-implantitis. Presence of Candida was assessed by traditional microbiological culture in blood agar or/and CHROMagar, though identification was also detected by quantitative real-time PCR, random amplified polymorphic DNA or ATB ID 32C. Dentate individuals and implants with peri-implantitis (range, 3-76.7\%) had a bigger presence of Candida. C. albicans was the most isolated species, followed by Candida parapsilosis, Candida tropicalis, and Candida dubliniensis.

Conclusion: Candida is part of the microbiological profile of the peri-implant sulcular fluid. More studies are needed to compare the link between Candida and other microorganisms and to discover the true role of these fungi in peri-implantitis.
\end{abstract}

Keywords: Candida, Peri-implantitis, Systematic review

\section{Background}

Oral rehabilitation with dental implants is a predictable and safe therapeutic procedure to treat tooth loss, in both partially and completely edentulous patients. Throughout the years, more advances have been made in the design, surface and chirurgical protocols of the implant systems, whose success can reach up to $95 \%$ of cases $[1,2]$.

Mechanical and biological complications are the main cause of dental implant failure. Peri-implantitis (PI) is a multifactorial infectious disease characterized by inflammation in the peri-implant mucosa and a progressive loss of supporting bone [3]. Although inflammatory

\footnotetext{
* Correspondence: Josemanuel.aguirre@ehu.eus

'Department of Stomatology II, University of the Basque Country (UPV/EHU), Barrio Sarriena s/n, 48940 Leioa, Vizcaya, Spain

Full list of author information is available at the end of the article
}

response is more pronounced in the tissues surrounding the implants than in those surrounding the teeth [4], the microbiological environment associated to PI is similar to the observed in conventional periodontal disease, which includes anaerobic Gram-negative bacteria, such as Prevotella nigrescens, Campylobacter rectus and Aggregatibacter actinomycetemcomitans [5]. Other microorganisms, for example fungi, like Candida, could also participate in the onset and development of PI, since Candida colonization and biofilm formation is relatively common on other metallic surfaces, like hip and knee prostheses [6, 7]. However, there is a direct association between surface roughness and hydrophobicity with biofilm development as surface topography influenced microbial adhesion. For instance, titanium is one of the biomaterials most resistant to microbial 
colonization and to the development of C. albicans and bacterial biofilms [8].

Candida is a commensal of the oral cavity that can be isolated from many healthy individuals but can trigger mucosa infections (candidiasis) associated to different predisposing factors, like immunodeficiency [9]. Subgingival sulcus can also play as a refuge for pathogenic fungi [10]. In addition, different species of Candida have already been associated with the maintenance of periodontal inflammation in periodontitis [11, 12]. Nevertheless, the mechanisms by which Candida may enhance bone resorption, especially in the jaws, are unclear.

Candida albicans is the species more frequently isolated in PI, developing thick biofilms over the periimplant surface [10]. Given its ability to adhere to the implant area in intimate contact with the bone, it has been hypothesized that Candida could also contribute to the progression of PI, but this link has yet to be elucidated.

The objective of this work is to make a systematic review of the literature, aiming to recognize the presence of different species of Candida in the peri-implant niche and to discuss its role in the pathogenesis and progression of peri-implantitis.

\section{Methods}

\section{Research strategy}

The methodological design of this study matches the PRISMA criteria and guidelines [13]. In this systematic review, we address the question "what is the role of Candida in the development of peri-implantitis?".

Two independent co-authors (ILIM, ACG) performed a systematic bibliographical research in PubMed (US National Gallery of Medicine), Scopus and Web of Science/Knowledge. The search strategy consisted in different combinations of the MeSH keywords: Candida, periimplantitis, periimplantitis, "dental implant" and implant (candida AND peri-implantitis; candida AND periimplantitis; candida AND dental implant; candida AND implant).

\section{Inclusion and exclusion criteria}

Inclusion criteria were studies published in English or Spanish until December 2020 in patients with dental implants and diagnosis of PI and/or analysing samples from the sulcular fluid surrounding dental implants. Among exclusion criteria were case reports, reviews, position papers, and author opinions. Moreover, those studies not available in full format and experimental studies were also excluded.

\section{Selection of the studies and data collection}

The study selection and data extraction were also performed by two reviewers (JMAU and ILIM). A third one
(JMAU) participated in the decision-making in case of doubt about the inclusion of the studies. Also, if essential data for the review was missing or unclear, the corresponding author clarified the problem.

The titles and abstracts of the retrieved references were screened for relevance and after this, the full texts of all articles potentially eligible were analysed against the inclusion/exclusion criteria. In order to collect the information of the different studies retrieved, a standard document was utilized for data regarding authors, year of publication, study design, diagnostic criteria, clinical specimens, implant systems used, and microbiological methods. In addition, quantitative data on the isolation of Candida and other microorganisms were collected for both peri-implantitis and healthy implants.

For categorical variables, we performed a descriptive statistical analysis to obtain frequencies and percentages, as well as to determine the average and standard deviation for quantitative variables.

\section{Risk of bias}

A modified Newcastle-Ottawa Scale (NOS) was used to assess the methodological quality of the included studies [14]. This system analyses the risk of bias of nonrandomized studies, taking into account three domains and eight items for cohort studies: selection, comparability and outcome. The total maximum score is 9; a study with a score from 7 to 9 has high quality; 4 to 6 , high risk of bias; and 0 to 3 , very high risk of bias.

\section{Results \\ Bibliographical search and retrieval}

The selection process of search and retrieval of literature is showed in Fig. 1. Initially, 1185 records were retrieved from databases, from which 41 were excluded due to not being published in English or Spanish, 131 because they were not made in humans and 87 for being duplicates. Thus, 926 articles were screened, but 691 were eliminated because they did not study the presence of Candida in dental implants, another 210 for being case reports, reviews or author opinions and other 10 for not being available in full-text.

After the detailed analysis, 15 articles studying the presence of Candida in patients with dental implants were included. However, during the extraction data process, we saw that only nine of them compared patients with and without PI, which accounted for the $0.78 \%$ of the initial number (Table 1) $[10,15-$ 22]. So, the remaining six manuscripts were discarded since they studied patients with dental implants but without diagnosis of the peri-implant status [2, 23-27]. 


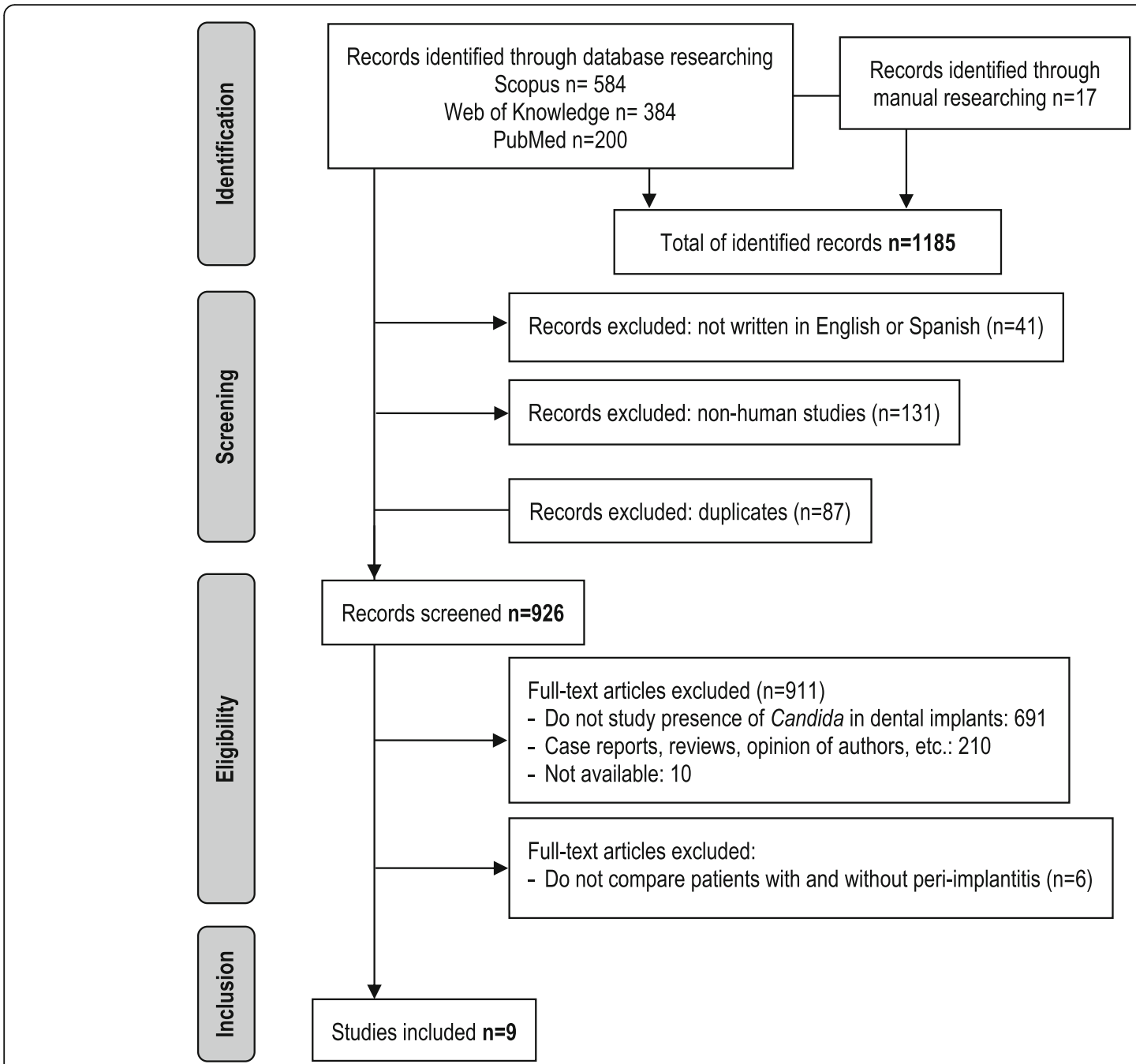

Fig. 1 PRISMA flow diagram. Synthesis of the bibliographical analysis

Table 1 Clinical data of the included studies

\begin{tabular}{|c|c|c|c|c|c|c|c|c|c|}
\hline \multirow[t]{2}{*}{ Authors and year } & \multirow[t]{2}{*}{ Country } & \multirow{2}{*}{$\begin{array}{l}\text { Assessment } \\
\text { of Candida }\end{array}$} & \multicolumn{3}{|c|}{ Patients } & \multirow{2}{*}{$\begin{array}{l}\text { Mean } \\
\text { age } \\
\text { (years) }\end{array}$} & \multicolumn{3}{|c|}{ Dental implants } \\
\hline & & & Total & $\mathrm{PI}$ & Healthy & & Total & PI & Healthy \\
\hline Rosenberg et al. 1991 [15] & USA & - & 75 & 11 & 64 & - & 83 & - & - \\
\hline Leonhardt et al. 1999 [16] & Sweden & Blood agar & 88 & 37 & 51 & 63 & - & - & - \\
\hline Listgarten et al. 1999 [17] & USA & Blood agar & 41 & 41 & 0 & 59 & 44 & 44 & 0 \\
\hline Albertini et al. 2015 [18] & Spain & CHROMagar & 33 & 33 & 0 & 67.1 & 48 & 48 & 0 \\
\hline Canullo et al. 2015 [19] & Italy & $\mathrm{qPCR}$ & 534 & 53 & 481 & 62,25 & 235 & 231 & 1276 \\
\hline Schwarz et al. 2015 [20] & Germany & $\mathrm{qPCR}$ & 29 & 19 & 10 & - & 29 & 19 & 10 \\
\hline Bertone et al. 2016 [21] & Argentine & CHROMagar & 40 & 40 & 0 & 56 & 89 & 49 & 40 \\
\hline Alrabiah et al. 2019 [10] & Saudi Arabia & CHROMagar & 84 & 43 & 41 & 53,65 & 84 & 43 & 41 \\
\hline Alsahhaf et al. 2019 [22] & Saudi Arabia & CHROMagar & 126 & 84 & 42 & 55,77 & 126 & 84 & 42 \\
\hline
\end{tabular}

Pl peri-implantitis 
Clinical and microbiological characteristics of the included studies

The microbiological analysis was performed, in all the studies, collecting samples from the sulcular fluid with sterile paper points for different periods. Presence of Candida was assessed by traditional microbiological culture in blood agar [16, 17] or/and CHROMagar [10, 18, $22,23]$. Identification of clinical isolates of different Candida species was also detected by either quantitative real-time PCR $[19,21]$, random amplified polymorphic DNA [22] or ATB ID 32 [18]. In all cases, the patients had not taken antibiotics, at least 2 months before taking the samples.

These studies analysed 626 patients, 361 with PI (57.7\%) and 265 without PI (42.3\%), whose mean age varied between 53 and 67 years. Data about gender was available in 5 studies [10, 18, 19, 21, 23], from which $20.3 \%$ were women ( 38 with PI and 33 without PI) and 79.7\% (162 with PI and 117 without PI) men. Curiously, two articles from Saudi Arabia did not include female patients [10, 23]. In total, 737 patients wearing dental implants were investigated, 400 (54.3\%) with periimplantitis and 337 (45.7\%) without PI (Table 1).

Only one study did not found Candida in the sulcular fluid [17]. The rest of the studies recognized a bigger presence of the fungi in the implants with PI (range, 3$76.7 \%$ ), in contrast to healthy ones (range, 9-50\%) [15, 16, 18, 19, 21-23]. Dentate patients also had more Candida in their implants than edentulous ones [16, 19]. Fungal colonization was observed only in dental implants with PI in three studies $[15,16,18]$.

C. albicans was the most isolated species, followed by Candida parapsilosis, Candida tropicalis, Candida dubliniensis, Candida boidinii, Candida guilliermondii, Candida krusei and Candida lusitaniae (Table 2). Rosenberg et al. [15] did not indicate the species of Candida. Most of the authors reported presence of $C$. albicans, as well as C. boidinii, C. dubliniensis, $C$. parapsilosis, C. tropicalis, C. guilliermondii, C. krusei and C. lusitaniae [10, 21-23]. None of the authors stated if these were pure or polifungal Candida biofilms [10, 21-23]. C. albicans alone was observed in three studies [16-18].

\section{Risk of bias in individual studies}

After applying modified NOS assessment, $22.2 \%$ of the studies revealed 9 stars, $44.5 \%$ of them 8 and $33.3 \%$ of them 7 (Table 3). Overall, risk of bias was low.

\section{Clinical and microbiological characteristics of the excluded studies}

The six articles excluded in this review analysed the presence of Candida in the sulcular fluid surrounding 362 dental implants [2, 23-27]. In most reports, $C$. albicans was isolated [2, 23, 25, 26]; however, $C$. dubliniensis, C. glabrata, Candida kefyr and Candida norvegensis were also observed [20, 24, 26] (Table 4). The presence of Candida was variable, affecting between 10 and $71 \%$ of the implants. The study of Peñarrocha et al. [24] was the only one in which no Candida was observed in the implants investigated. This absence of Candida colonization might be related to the small sample size (20 patients) and to the fact that they look for the presence of $C$. albicans and no other species of Candida.

Gomes et al. [26] described that the quantity of Candida was bigger at 8 months was higher than that observed at 4 months after implant placement. Mencio et al. [2] only observed the presence of $C$. albicans in implants with cemented implantabutment connections but not in those with screwed implant-abutment connections. In addition, Kilic et al. [23] found more Candida colonization in patients with bar-retained overdentures (25\%) than in those with locator-retained overdentures (19\%) (Table 3).

Table 2 Microbiological findings of the included studies. Species of Candida

\begin{tabular}{|c|c|c|c|c|}
\hline \multirow[t]{2}{*}{ Authors and year } & \multicolumn{3}{|c|}{ Candida presence (\%) } & \multirow[t]{2}{*}{ Species of Candida } \\
\hline & Total & PI & Healthy & \\
\hline Rosenberg et al. 1991 [15] & 32 & 32 & 0 & - \\
\hline Leonhardt et al. 1999 [16] & 27 & 27 & 0 & C. albicans \\
\hline Albertini et al. 2015 [18] & 3 & 3 & - & C. albicans \\
\hline Canullo et al. 2015 [19] & 13.5 & 16.9 & $15.9 \%$ & C. albicans \\
\hline Schwarz et al. 2015 [20] & 12.9 & 15.8 & 10 & C. albicans, C. boidinii, C dubliniensis \\
\hline Bertone et al. 2016 [21] & 51.5 & 53 & 50 & C. albicans, C. dubliniensis, C. parapsilosis, C. tropicalis, C. guilliermondii, C. krusei, C. Iusitaniae \\
\hline Alrabiah et al. 2019 [10] & 44.5 & 76.7 & 12.2 & C. albicans, C. tropicalis, C. parapsilosis \\
\hline Alsahhaf et al. 2019 [22] & 43 & 76.2 & 9.8 & C. albicans, C. tropicalis, C. parapsilosis \\
\hline
\end{tabular}


Table 3 Quality assessment of the included studies. NOS tool

\begin{tabular}{|c|c|c|c|c|}
\hline \multirow[t]{2}{*}{ Authors, year } & \multirow{2}{*}{$\begin{array}{l}\text { Type of } \\
\text { study }\end{array}$} & \multicolumn{3}{|c|}{ Newcastle-Ottawa Scale (NOS) } \\
\hline & & Selection & Comparison & Exposure/outcome \\
\hline Rosenberg et al. 1991 [15] & Case-control & $\star \star$ & $\star \star$ & $\star \star \star$ \\
\hline Leonhardt et al. 1999 [16] & Case-control & $\star \star$ & $\star \star$ & $\star \star \star$ \\
\hline Listgarten et al. 1999 [17] & Cohort & $\star \star \star$ & $\star \star$ & $\star \star \star$ \\
\hline Albertini et al. 2015 [18] & Cohort & $\star \star \star$ & $\star \star$ & $\star \star \star$ \\
\hline Canullo et al. 2015 [19] & Case-control & $\star \star$ & $\star \star$ & $\star \star \star$ \\
\hline Schwarz et al. 2015 [20] & Case-control & $\star \star \star$ & $\star \star$ & $\star \star \star$ \\
\hline Bertone et al. 2016 [21] & Cohort & $\star \star \star$ & $\star \star$ & $\star \star \star$ \\
\hline Alrabiah et al. 2019 [10] & Case-control & $\star \star \star \star$ & $\star \star$ & $\star \star \star$ \\
\hline Alsahhaf et al. 2019 [22] & Case-control & $\star \star \star \star ~$ & $\star \star$ & $\star \star \star$ \\
\hline
\end{tabular}

\section{Discussion}

Candida is a heterogeneous fungal genus composed by more than 150 species. Although some species of Candida coexist as human commensals, they can cause superficial and systemic infections under certain circumstances [28]. Most candidiasis are caused by C. albicans, but in the recent years other non-C. albicans species have manifested a pathogenic capacity. Among the most frequently isolated from clinical specimens are Candida glabrata, C. parapsilosis and C. tropicalis [29].

The pathogenicity of Candida responds to a set of virulence factors, including dimorphism, secretion of hydrolytic enzymes (proteases, lipases and haemolysins) and adhesion and biofilm formation on the mucous epithelium and on medical devices [30, 31]. Formation of biofilms is a complex sequential process that depends on the invasive agent and the structure on which it is hosted [32]. Yeast colonization of biotic and abiotic surfaces is the first step in the development of biofilms, followed by cell division and microcolonies generation that contribute to the maturation of a biofilm characterized by the presence of hyphae and yeasts (sessile cells) embedded in an extracellular matrix and, finally, the detachment of some of these cells [33]. The release of planktonic cells into the environment allows them to colonize new surfaces and to develop new foci of candidiasis.
Because the diagnostic criteria of the peri-implant diseases have been in constant change, the diagnosis of peri-implantitis in the included studies have differed from one to another, due to being published over a long period of time, from 1991 to 2020. Yet most of the reviewed studies collected data about bleeding and/or suppuration on probing, probing depth and radiographic bone loss. Moreover, implant mobility and presence of keratinized mucosa was evaluated in three studies [15, $16,20,21]$. For all these reasons, although it cannot be guaranteed that all the implants studied in this work have been correctly categorized as healthy or diseased, the margin of error could not be very wide [5, 34, 35]. In regards to the risk factor of PI, none of the studies excluded patients with history of periodontitis and two discarded smokers [10, 22]. Still, only one of the nine selected articles did not state whether they found Candida or not [17].

According to the included studies of this review, implants with peri-implantitis (range, 3-76.7\%) had a higher presence of Candida than those without periimplantitis (range, 9-50\%). However, we do not know why prevalence of Candida was significantly bigger in the studies with individuals form Saudi Arabia [10, 22]. Since fungal assessment and sample size were similar to other studies $[16,18]$, we believe these particular results may be related to special geographical and sociocultural

Table 4 Clinical data and microbiological findings of the excluded studies*

\begin{tabular}{|c|c|c|c|}
\hline \multirow[t]{2}{*}{ Authors and year (country) } & \multirow{2}{*}{$\begin{array}{l}\text { Patients } \\
\text { (implants) }\end{array}$} & \multicolumn{2}{|c|}{ Isolation of Candida from clinical specimens } \\
\hline & & $\%$ & Species \\
\hline Kilic et al. 2014 (Turkey) [23] & $37(37)$ & 71 & C. albicans, C. glabrata, C. kefyr, C. norvegensis \\
\hline Peñarrocha et al. 2015 (Spain) [24] & $20(43)$ & 0 & - \\
\hline Canullo et al. 2015 (Italy) [25] & $40(80)$ & 15 & C. albicans, C. dubliniensis \\
\hline Gomes et al. 2017 (Brazil) [26] & $14(60)$ & - & C. albicans, C. dubliniensis \\
\hline Mencio et al. 2017 (Italy) [2] & $20(50)$ & 10 & C. albicans \\
\hline Ju et al. 2019 (South Korea) [27] & $92(92)$ & 13 & - \\
\hline
\end{tabular}

*These articles were excluded due to the absence of any peri-implant diagnostic criteria 
factors, such as diet, and the fact that these authors excluded female patients and smokers [10, 22].

Moreover, the fact that $10-71 \%$ of implants, regardless of peri-implantitis, showed the presence of this fungus demonstrates that colonization of Candida in the periimplant environment is independent of the disease. Also, because a slightly higher number of patients with barretained overdentures had Candida, in contrast to locator-retained overdentures, time and hygiene of implants might also be important factors of fungal colonization.

Schwarz et al. [20] were the sole authors to state a direct relationship between Candida and other microorganisms. Thereby, from three implants with PI, C. boidinii was isolated alongside Mycoplasma salivarum, Veillonella parvula, Porphyromonas gingivalis, Parvimonas micra and Tannerella forsythia in one of them, and in the other two, $C$. albicans was also found with $V$. parvula, $T$. forsythia, $M$. salivarum, $P$. gingivalis and $P$. micra. On the other hand, C. dubliniensis was accompanied by M. salivarum, $V$. parvula, Staphylococcus aureus, P. micra and T. forsythia in one healthy implant. The latter species of Candida, C. dubliniensis has been isolated from patients suffering from different oral pathologies, resembling $C$. albicans in many virulence factors including hypha formation and hydrolytic enzyme production [36, 37]. In this context, Candida colonization could be linked to the presence of other periodontopathogens, like T. forsythia, $P$. micra or P. gingivalis. Although the exact role of Candida in the beginning of the peri-implant disease is unknown, we believe that this fungus could play an important function in the latter stages of PI, when the bacterial microenvironment is already established, as demonstrated in experimental studies [38].

Knowledge of the involvement of Candida infection in disorders of bone remodelling is limited, but it has been described in Candida arthritis and osteomyelitis [39, 40], nosological entities described very rarely in the jaws [41, 42]. Candida arthritis and osteomyelitis develop by haematogenous invasion, mainly in patients with immunodeficiency, being C. albicans is usually the most frequently isolated, although C. tropicalis, C. glabrata and C. parapsilosis has also been isolated [40]. As in the latter processes, Candida would act as a modifying agent in chronic inflammation around dental implants that activates the bone resorption response.

Anaerobiosis, as occurs in peri-implant pockets, can promote the virulence of $C$. albicans, increasing the activity of secreted aspartyl proteinases (Sap) [43]. These Sap proteins are associated to Candida adherence, tissue damage and modulation of immune response, maintaining inflammatory stimuli that attract other periodontopathogens [44, 45]. This role of Saps is important because the ability to form thick biofilms is easier for $C$. albicans, both under aerobic and anaerobic conditions, whereas for the rest of the species of Candida, growth is much greater only under aerobic conditions [46]. C. albicans hyphae secrete candidalysin, a 31-amino-acid peptide toxin that damages the epithelial cells and has an immunomodulatory capacity by binding to epidermal growth factor receptor (ErbB1 or Her1) [47]. Yeast and hyphal morphologies are present during asymptomatic C. albicans colonization of human mucosal surfaces. However, hypha formation can lead to candidalysin secretion, tissue damage and immune modulation (Fig. 2). Furthermore, C. albicans $95-\mathrm{kDa}$ metallopeptidase, localized in cell wall, owns the capacity to destroy different elements of the peri-implant soft and hard tissues like type I collagen (connective tissue, alveolar bone and cement), type IV collagen (basement membrane of the mucosa), fibronectin (periodontal ligament) and laminin (basement membrane of the mucosa and cement) [48-50].

Interestingly, one study [22] pointed that patients with dental implants in which Candida was isolated, also had a higher presence of these fungi at the buccal, lingual and palatal mucosa. Although this study did not differentiate between implants with and without PI, it evidences the existence of an oral reservoir for Candida that facilitates the entry of this fungus into the peri-implant sulcus.

This systematic review has limitations. First, only nine studies analysed the presence of Candida in patients with peri-implantitis including very heterogeneous samples (range, 20-126 studied specimens). Second, few studies reported the number of Candida colonyforming units (CFU), which is a fundamental data for the mycological analysis $[9,51]$. Alrabiah et al. [10] showed significant differences in the quantity of Candida between specimens from patients suffering PI (3147.54 CFU/mL) and from patients without PI $(496.68 \pm 100.2 \mathrm{CFU} / \mathrm{mL})$. These findings are similar to those found by Alsahhaf et al. [22] (2316.26 vs 177.6 $\mathrm{CFU} / \mathrm{ml}$ ). Third, it was impossible to analyse the differences of Candida in patients with PI, regarding the type, composition, design and surface of the implants, because only Leonhardt et al. [16], said that their implants were Nobel Biocare AB (Gothenburg, Sweden). We are convinced of the importance of studying the implant characteristics, since they can be strongly related to colonization and infection, according to how they allow Candida adherence. There is a strong association between implant properties and microbial adhesion, titanium being one of the most resistant to Candida colonization and biofilm development [8]. Moreover, there is a considerable heterogeneity of the selected studies regarding the microbial methods and study design then results obtained from different microbiological methods did not allow for a direct comparison. 


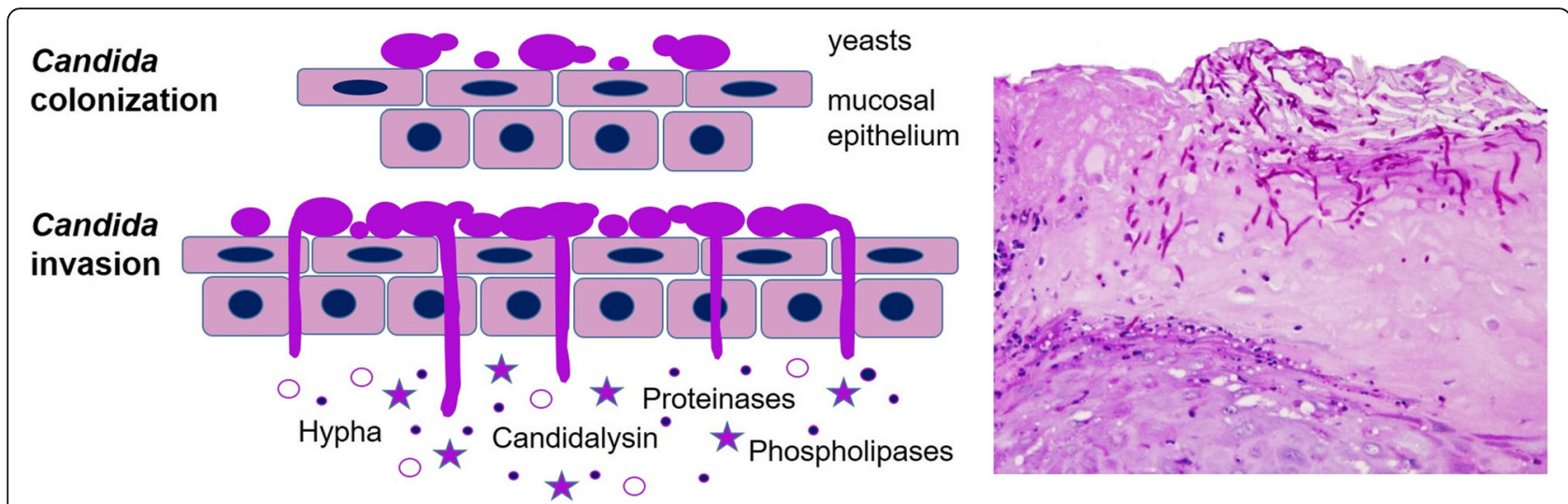

Fig. 2 Candida albicans virulence factors. Mechanisms by which C. albicans promotes colonization and invasion of mucosal cells

\section{Conclusions}

In summary, Candida is a common inhabitant of the peri-implant sulcular sulcus microbial environment, both in healthy implants and in those from people suffering from PI. However, Candida presence is more common in peri-implantitis. This presence and the Candida concentrations in the peri-implant tissue can be related to the lapse of time dental implants have been in the oral cavity. In addition, the quantity of Candida in the sulcular fluid surrounding the implants might rely on the presence of other periodontopathogens, such as $V$. parvula, T. forsythia, M. salivarum, $P$. gingivalis or $P$. micra. Although, $C$. albicans, $C$. parapsilosis and $C$. tropicalis are the most common species in periimplantitis, others have also been identified, such as $C$. dubliniensis, C. boidinii, C. guilliermondii, C. krusei and C. lusitaniae, but in a very low frequency. Betterdesigned studies are needed, with larger patient samples, to unravel whether there is a relevant role for Candida in the etiopathogenesis of peri-implantitis and dental implant failure.

\section{Acknowledgements}

Not applicable

\section{Authors' contributions}

ILIM made substantial contributions to the conception and design of the work and acquisition, analysis, and interpretation of data. ACCG contributed to the conception of the work and of data. GQA contributed to interpretation of data and substantively revised the draft. JMAU made substantial contributions to the conception of the work, interpretation of data, and substantively revised the draft. The authors read and approved the final manuscript.

\section{Funding}

This research did not receive any specific grant from funding agencies in the public, commercial or not-for-profit sectors. The authors have no conflict of interest related to the study.

\section{Availability of data and materials}

All data generated or analysed during this study are included in this published article [and its supplementary information files].

\section{Declarations}

Ethics approval and consent to participate

Not applicable.

Consent for publication

Not applicable.

\section{Competing interests}

Irene Lafuente-Ibáñez de Mendoza, Amaia Cayero-Garay, Guillermo QuindósAndrés and José Manuel Aguirre-Urizar declare that they have no competing interests.

\section{Author details}

'Department of Stomatology II, University of the Basque Country (UPV/EHU), Barrio Sarriena s/n, 48940 Leioa, Vizcaya, Spain. ${ }^{2}$ Department of Immunology, Microbiology and Parasitology, University of the Basque Country (UPV/EHU), Leioa, Vizcaya, Spain.

Received: 9 February 2021 Accepted: 30 March 2021

Published online: 17 June 2021

\section{References}

1. Karoussis IK, Salvi GE, Heitz-Mayfield LJ, Brägger U, Hämmerle CH, Lang NP. Long-term implant prognosis in patients with and without a history of chronic periodontitis: a 10-year prospective cohort study of the IT| ${ }^{\oplus}$ Dental Implant System. Clin Oral Implants Res. 2003;14(3):329-39. https://doi.org/1 0.1034/j.1600-0501.000.00934.x.

2. Mencio F, De Angelis F, Papi P, Rosella D, Pompa G, Di Carlo S. A randomized clinical trial about presence of pathogenic microflora and risk of peri-implantitis: comparison of two different types of implant-abutment connections. Eur Rev Med Pharmacol Sci. 2017;21 (7):1443-51.

3. Schwarz F, Derks J, Monje A, Wang HL. Peri-implantitis. J Clin Periodontol. 2018;45:S246-66. https://doi.org/10.1111/jcpe.12954.

4. Berglundh T, Zitzmann NU, Donati M. Are peri-implantitis lesions different from periodontitis lesions? J Clin Paeriodontol. 2011;38:188-202. https://doi. org/10.1111/j.1600-051X.2010.01672x.

5. Persson GR, Renvert S. Cluster of bacteria associated with periimplantitis. Clin Implant Dent Rel Res. 2014;16(6):783-93. https://doi. org/10.1111/cid.12052.

6. Bürgers $R$, Hahnel $S$, Reichert $T E$, Rosentritt M, Behr M, Gerlach $T$, et al. Adhesion of Candida albicans to various dental implant surfaces and the influence of salivary pellicle proteins. Acta Biomat. 2010;6(6):2307-13. https://doi.org/10.1016/j.actbio.2009.11.003.

7. Cobo F, Rodríguez-Granger J, Sampedro A, Aliaga-Martínez L, Navarro-Marí JM. Candida prosthetic joint infection. A review of treatment methods. Bone Joint Inf. 2017;2(2):114-21. https://doi.org/10.7150/jbji.17699.

8. De-la-Pinta I, Cobos M, Ibarretxe J, Montoya E, Eraso E, Guraya T, et al. Effect of biomaterials hydrophobicity and roughness on biofilm development. 
J Mater Sci Mater Med. 2019;30(7):77. https://doi.org/10.1007/s10856-01 9-6281-3.

9. Aguirre-Urizar JM. Candidiasis orales. Rev Iberoam Micol. 2002;19(1):17-21.

10. Alrabiah M, Alshagroud RS, Alsahhaf A, Almojaly SA, Abduljabbar T, Javed F. Presence of Candida species in the subgingival oral biofilm of patients with peri-implantitis. Clin Implants Dent Relat Res. 2019;21(4):781-5.

11. Urzúa B, Hermosilla G, Gamonal J, Morales-Bozo I, Canals M, Barahona, et al. Yeast diversity in the oral microbiota of subjects with periodontitis: Candida albicans and Candida dubliniensis colonize the periodontal pockets. Sabouraudia. 2008;46(8):783-93. https://doi.org/10.1080/13693780802 060899

12. De la Torre J, Quindós G, Marcos-Arias C, Marichalar-Mendia X, Gainza ML,

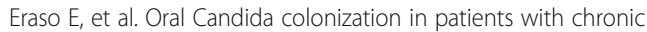
periodontitis. Is there any relationship? Rev Iberoam Micol. 2018;35(3):134-9. https://doi.org/10.1016/j.riam.2018.03.005.

13. Moher D, Liberati A, Tetzlaff J, Altman DG. Preferred reporting items for systematic reviews and meta-analyses: the PRISMA statement. An Int Med. 2009;151(4):264-9. https://doi.org/10.7326/0003-4819-151-4-2009081 80-00135.

14. Wells GA, Tugwell P, O'Connell D, Welch V, Peterson J, Shea B et al. The Newcastle-Ottawa Scale (NOS) for assessing the quality of nonrandomized studies in meta-analyses (2015). Retrieved from http://www.ohri.ca/progra ms/clinical_epidemiology/oxford.asp

15. Rosenberg ES, Torosian JP, Slots J. Microbial differences in 2 clinically distinct types of failures of osseointegrated implants. Clin Oral Implants Res. 1991;2(3):135-44. https://doi.org/10.1034/j.1600-0501.1991.020306.x.

16. Leonhardt Å, Renvert S, Dahlén G. Microbial findings at failing implants. Clin Oral Implants Res. 1999;10(5):339-45. https://doi.org/10.1034/j.1600-0501.1 999.100501.x.

17. Listgarten MA, Lai CH. Comparative microbiological characteristics of failing implants and periodontally diseased teeth. J Periodontol. 1999;70(4):431-7. https://doi.org/10.1902/jop.1999.70.4.431.

18. Albertini M, López-Cerero L, O'Sullivan MG, Chereguini CF, Ballesta S, Ríos, et al. Assessment of periodontal and opportunistic flora in patients with peri-implantitis. Clin Oral Implants Res. 2015;26(8):937-41. https://doi.org/1 $0.1111 / \mathrm{dr} .12387$

19. Canullo L, Peñarrocha-Oltra D, Covani U, Rossetti PHO. Microbiologic and clinical findings of implants in healthy condition and with peri-implantitis. Int J Oral Maxillofac Implants. 2015;30(4):834-42. https://doi.org/10.11607/ jomi.3947.

20. Canullo L, Penarrocha-Oltra D, Soldini C, Mazzocco F, Penarrocha M, Covani U. Microbiological assessment of the implant-abutment interface in different connections: cross-sectional study after 5 years of functional loading. Clin Oral Implants Res. 2015;26(4):426-34. https://doi.org/10.1111/clr.12383.

21. Schwarz F, Becker K, Rahn S, Hegewald A, Pfeffer K, Henrich B. Real-time PCR analysis of fungal organisms and bacterial species at peri-implantitis sites. Int J Implant Dent. 2015;1(1):9. https://doi.org/10.1186/s40729-015-0010-6.

22. Bertone $A M$, Rosa AC, Nastri N, Santillán HD, Ariza Y, lovannitti CA, et al. Genetic-relatedness of peri-implants and buccal Candida albicans isolates determined by RAPD-PCR. Acta Odonto Lat. 2016;29(3):197-205.

23. Alsahhaf A, Al-Aali KA, Alshagroud RS, Alshiddi IF, Alrahlah A, Abduljabbar T, et al. Comparison of yeasts species in the subgingival oral biofilm of individuals with type 2 diabetes and peri-implantitis and individuals with peri-implantitis without diabetes. J Periodontol. 2019;90(12):1383-9. https:// doi.org/10.1002/JPER.19-0091.

24. Kilic K, Koc AN, Tekinsen FF, Yildiz P, Kilic D, Zararsiz G, et al. Assessment of Candida species colonization and denture-related stomatitis in bar-and locator-retained overdentures. J Implantol. 2014;40(5):549-56. https://doi. org/10.1563/AAID-JOI-D-12-00048.

25. Peñarrocha-Oltra D, Rossetti PH, Covani U, Galluccio F, Canullo L. Microbial leakage at the implant-abutment connection due to implant insertion maneuvers: cross-sectional study 5 years postloading in healthy patients. J Oral Implantol. 2015;41(6):e292-6. https://doi.org/10.1563/aa id-joi-D-14-00235.

26. Gomes JA, Sartori IA, Able FB, de Oliveira Silva TS, do Nascimento C. Microbiological and clinical outcomes of fixed complete-arch mandibular prostheses supported by immediate implants in individuals with history of chronic periodontitis. Clin Oral Implants Res. 2017;28(6):734-41. https://doi. org/10.1111/clr.12871.

27. Ju HM, Ahn YW, Jeong SH, Jeon HM, Kim KH, Song BS, et al. Characteristics of patients who perceive dental treatment as a cause of oral mucosal lesions. J Oral Sci. 2019;61(3):468-74. https://doi.org/10.2334/josnusd.180292.

28. Araújo D, Henriques M, Silva S. Portrait of Candida species biofilm regulatory network genes. Trend Microbiol. 2017;25(1):62-75. https://doi.org/10.1016/j. tim.2016.09.004.

29. Quindós G, Marcos-Arias C, San-Millán R, Mateo E, Eraso E. The continuous changes in the aetiology and epidemiology of invasive candidiasis: from familiar Candida albicans to multiresistant Candida auris. Int Microbiol. 2018; 21(3):107-17. https://doi.org/10.1007/s10123-018-0014-1.

30. Berman J, Sudbery PE. Candida albicans: a molecular revolution built on lessons from budding yeast. Nat Rev Genet. 2002;3(12):918-30. https://doi. org/10.1038/nrg948.

31. Mayer FL, Wilson D, Hube B. Candida albicans pathogenicity mechanisms. Virulence. 2013;4(2):119-28. https://doi.org/10.4161/viru.22913.

32. Nobile CJ, Fox EP, Nett JE, Sorrells TR, Mitrovich QM, Hernday AD, et al. A recently evolved transcriptional network controls biofilm development in Candida albicans. Cell. 2012;148(1-2):126-38. https://doi.org/10.1016/j.cell.2 011.10.048.

33. Finkel JS, Mitchell AP. Genetic control of Candida albicans biofilm development. Nat Rev Microbiol. 2012;9(2):109-18.

34. Kumar PS, Mason MR, Brooker MR, O'Brien K. Pyrosequencing reveals unique microbial signatures associated with healthy and failing dental implants. J Clin Periodontol. 2012;39(5):425-33. https://doi.org/10.1111/j.1600-051X.2 012.01856.x

35. Carcuac O, Berglundh T. Composition of human peri-implantitis and periodontitis lesions. J Dent Res. 2014;93(11):1083-8. https://doi.org/10.1177/ 0022034514551754.

36. Gutiérrez J, Morales P, González MA, Quindós G. Candida dubliniensis, a new fungal pathogen. J Basic Microbiol. 2002;42(3):207-27. https://doi.org/10.1 002/1521-4028(200206)42:3<207::AID-JOBM207>3.0.CO;2-C.

37. Sahand IH, Maza JL, Eraso E, Montejo M, Moragues MD, Aguirre JM, et al. Evaluation of CHROM-Pal medium for the isolation and direct identification of Candida dubliniensis in primary cultures from the oral cavity. J Med Microbiol. 2009;58:1437-42.

38. Cavalcanti YW, Wilson M, Lewis M, Del-Bel-Cury AA, da Silva WJ, Williams DW. Modulation of Candida albicans virulence by bacterial biofilms on titanium surfaces. Biofoul. 2016;32(2):123-34. https://doi.org/10.1080/0892 7014.2015.1125472.

39. Slenker AK, Keith SW, Horn DL. Two hundred and eleven cases of Candida osteomyelitis: 17 case reports and a review of the literature. Diagn Microbiol Infect Dis. 2012;73(1):89-93. https://doi.org/10.1016/j.dia gmicrobio.2012.02.004.

40. Gamaletsou MN, Rammaert B, Bueno MA, Sipsas NV, Moriyama B, Kontoyiannis $D$, et al. Candida arthritis: analysis of 112 pediatric and adult cases. Open Forum Infect Dis. 2016:3(1):ofv207. https://doi.org/10.1093/ofid/ofv207.

41. Attie MD, Anderson IA, Portnof J. Mandibular osteomyelitis associated with Candida albicans in marijuana and heroin abusers. Ann Maxillofac Surg. 2018;8(2):355-7. https://doi.org/10.4103/ams.ams_83_18.

42. Kaushal D, Sharma A, Kesarwani A, Kalita JM. Chronic Candida osteomyelitis of hard palate and nose: a diagnostic quandary. Med Mycol Case Rep. 2019; 24:1-4. https://doi.org/10.1016/..mmcr.2019.01.003.

43. Rosa EAR, Rached RN, Ignácio SA, Rosa RT, da Silva WJ, Yau JYY, et al. Phenotypic evaluation of the effect of anaerobiosis on some virulence attributes of Candida albicans. J Med Microbiol. 2008;57(10):1277-81. https:// doi.org/10.1099/jmm.0.2008/001107-0.

44. Naglik JR, Challacombe SJ, Hube B. Candida albicans secreted aspartyl proteinases in virulence and pathogenesis. Microbiol Mol Biol Rev. 2003; 67(3):400-28. https://doi.org/10.1128/MMBR.67.3.400-428.2003.

45. Sardi JCO, Scorzoni L, Bernardi T, Fusco-Almeida AM, Giannini MM. Candida species: current epidemiology, pathogenicity, biofilm formation, natural antifungal products and new therapeutic options. J Med Microbiol. 2008; 62(1):10-24.

46. Thein ZM, Samaranayake YH, Samaranayake LP. In vitro biofilm formation of Candida albicans and non-albicans Candida species under dynamic and anaerobic conditions. Arch Oral Biol. 2007;52(8):761-7. https://doi.org/10.101 6/j.archoralbio.2007.01.009.

47. Naglik JR, Gaffen SL, Hube B. Candidalysin: Discovery and function in Candida albicans infections. Curr Opin Microbiol. 2019:52:100-9. https://doi. org/10.1016/j.mib.2019.06.002.

48. Rodier MH, El Moudni B, Kauffmann-Lacroix C, Daniault G, Jacquemin JL. A Candida albicans metallopeptidase degrades constitutive proteins of 
extracellular matrix. FEMS Microbiol Let. 1999;177(2):205-10. https://doi. org/10.1111/j.1574-6968.1999.tb13733.x.

49. Embery G, Waddington RJ, Hall RC, Last KS. Connective tissue elements as diagnostic aids in periodontology. Periodontol 2000. 2000;24(1):193-214.

50. Canabarro A, Valle C, Farias MR, Santos FB, Lazera M, Wanke B. Association of subgingival colonization of Candida albicans and other yeasts with severity of chronic periodontitis. J Periodontol Res. 2013;48(4):428-32. https://doi.org/10.1111/jre.12022.

51. Tooyama H, Matsumoto T, Hayashi K, Kurashina K, Kurita H, Uchida M, et al. Candida concentrations determined following concentrated oral rinse culture reflect clinical oral signs. BMC Oral Health. 2015;15(1):150. https://doi. org/10.1186/s12903-015-0138-z

\section{Publisher's Note}

Springer Nature remains neutral with regard to jurisdictional claims in published maps and institutional affiliations.

\section{Submit your manuscript to a SpringerOpen ${ }^{\circ}$ journal and benefit from:}

- Convenient online submission

- Rigorous peer review

- Open access: articles freely available online

High visibility within the field

- Retaining the copyright to your article

Submit your next manuscript at $\boldsymbol{\nabla}$ springeropen.com 